جيوكيميائية الفوسفوريت والصخور المصاحبة لها ضمن تكوين عكاشات (الباليوسين الأوسط) في منجم عكاشات، الصحراء الغربية العراقية. الجزء الثاني: العناصر الأثرية

$$
\text { قسم علوم الأرض - كلية العلوم الداغ }
$$

\author{
قتيبة توفيق اليوزبكي \\ مركز بحوث السدود والموارد المائية

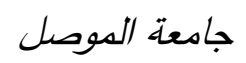

$$
\text { (تاريخ الاستلام 2019/7/18 تاريخ القبول 2019/11/28) }
$$

\begin{abstract}
الملخص
يعد تكوين عكاشـات من التكوينات المهمـة نظرا لأحتوائه على وحدة الهري التي تتكون من صخور الفوسفورايت الغنية بخامس أوكسيد الفسفور والصخور الفوسفاتية. تتكون هذه الصخور بشكل رئيس من معادن

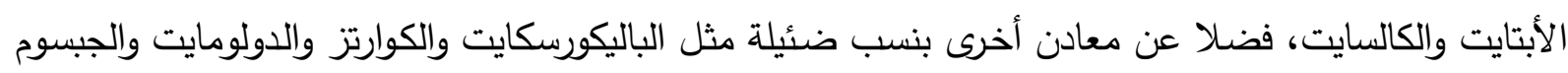

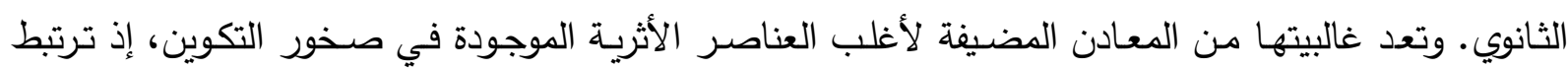

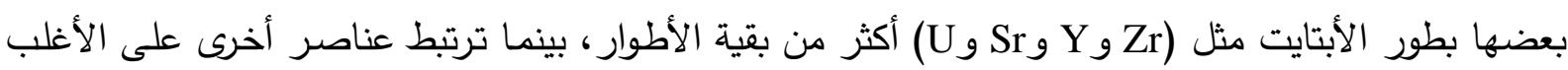

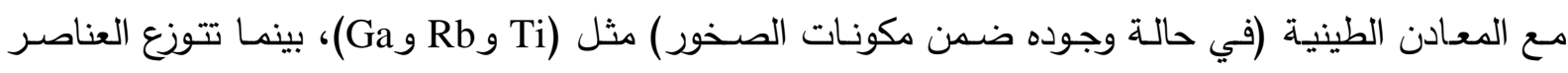

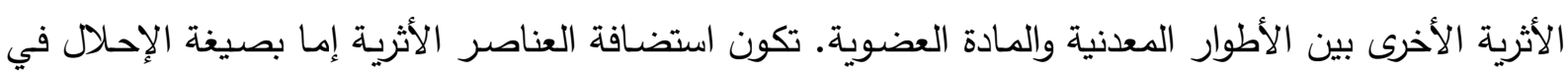

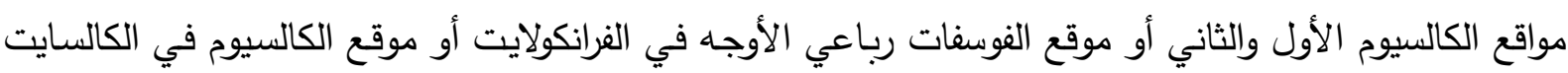

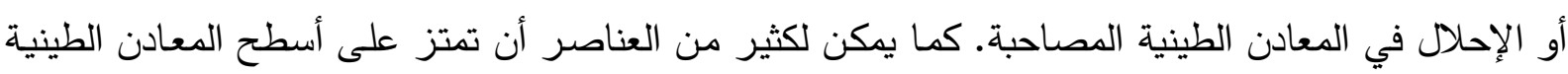
أو المادة العضوية أو داخل القناة البلورية للفرانكولايت. الكلمات الدالة: جيوكيميائية الفوسفورايت، تكوين عكاشات، الباليوسين الأوسط، منجم عكاشات، العناصر الأثرية.
\end{abstract}

\title{
Geochemistry of Phosphorite and Associated Rocks of Akashat Formation (Middle Paleocene) in Akashat Mine, Iraqi Western Desert. Part II: Trace Elements
}

\author{
Kotayba, T. Al-Youzbakey \\ Dams and Water Resources Research Center \\ University of Mosul
}

\author{
Salim, M. Al-Dabbagh \\ Department of Geology \\ College of Sciences \\ University of Mosul
}

\section{ABSTRACT}

Akashat Formation is an important formation due to its content of the Hirri member, which includes phosphorites and phosphatic limestones, that are rich in $\mathrm{P}_{2} \mathrm{O}_{5}$. These rocks are mainly composed of apatite and calcite. In addition to other minor and trace minerals like palygorskite, quartz, dolomite and secondary gypsum. All these minerals are hosted the most trace elements in the Akashat rocks. $\mathrm{U}, \mathrm{Sr}, \mathrm{Y}$ and $\mathrm{Zr}$ are related to apatite more than other minerals. While $\mathrm{Ga}, \mathrm{Rb}$ and $\mathrm{Ti}$ are almost correlated 
with the clay minerals. The rest trace elements are distributed among other minerals and organic matter. The hosting of trace elements by a mineral takes place in many cases as substituted in $\mathrm{Ca}(\mathrm{I}), \mathrm{Ca}(\mathrm{II})$ and phosphate tetrahedron in Francolite, Ca site in calcite, in clay mineral phases, or adsorbed on clay mineral faces, organic matters and in the crystal channel of francolite.

Keywords: Phosphorite Geochemistry, Akashat Formation, Middle Paleocene, Akashat Mine, Trace Elements

\section{المقدمة}

يضـم تكوين عكاشـات ثنلاث وحدات طباقيـة هي وحدة الطريفاوي (الباليوسين الأسفل) ووحدة الهـري

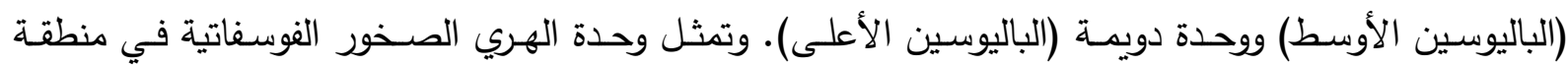

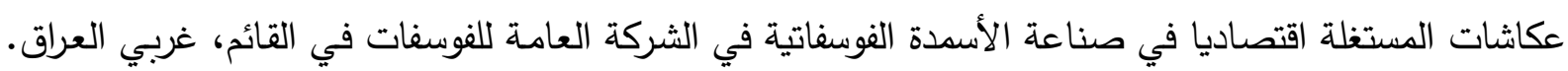

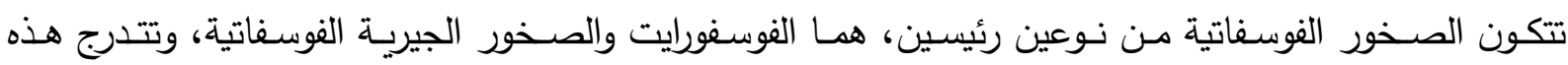
الصخور الواحدة تجاه الأخرى وفق محتواها من الحبيبات الفوسفاتية، ونوع المادة السمنتية (كلسية أو فوسفاتية) (اليوزبكي، 2004).

أشـارت العديد من التحاليل المعدنيـة الى ان الفرانكولايت يمثل المعدن الرئيس في فوسفورايت تكوين عكاثات، ويمثل الكالسايت المعدن الثانوي المصاحب له، في حين تنعكس النسبة في الصخور الجيرية الفوسفاتية

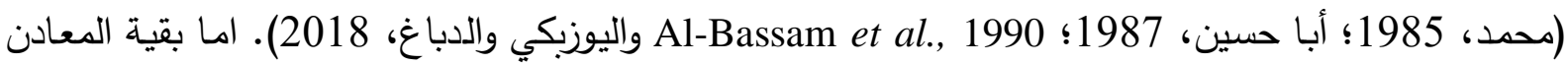

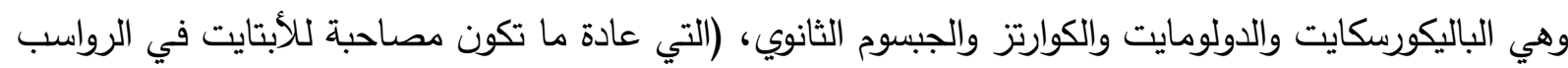
البحرية (Benmre et al., 1983))، فتوجد بنسب ضئيلة ومتباينة بين الفوسفورايت والصخور الجيرية الفوسفاتية وكذلك بين سحناتها (اليوزبكي، 2004 واليوزبكي والدباغ، 2019)، لذانلك تتوزع الأكاسيد الرئيسة والعناصر الأثرية بثكل رئيس بين الفرانكولايت والكالسايت والمعادن الطينية.

يمثل أوكسيد الكالسيوم وخامس اوكسيد الفنفور والفلور المكونات الرئيسة لهعدن الفرانكولايت، وترتبط

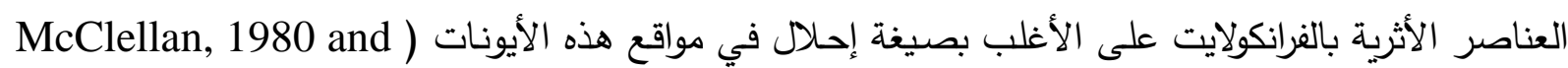
Nathan, 1984 أو ممتزة عليها (Altschuler, 1980)، إذ يساعد المحتوى القليل من المعادن الطينية على الطي

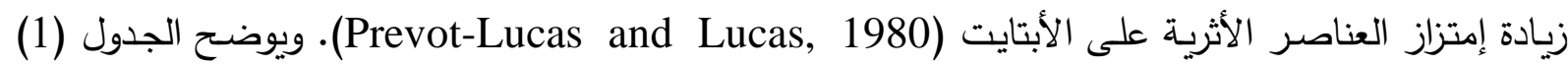
بعض الأيونات الرئيسة والأثرية التي تحل في مواقع الأتيات الأيونات الككونة لمعدن الفرانكولايت. الجدول 1: الأيونات القابلة للأحلال في مواقع بلورة الفلورأبتايت عن (McClellan, 1980).

\begin{tabular}{|c|c|}
\hline الأيـونات التي تحل محلها & الأيونات التي تشغل \\
\hline $\begin{array}{l}\mathrm{Na}^{+}, \mathrm{Sr}^{2+}, \mathrm{Mn}^{2+}, \mathrm{K}^{+}, \mathrm{U}^{4+}, \mathrm{Ba}^{2+}, \mathrm{Mg}^{2+}, \mathrm{Y}^{3+} \& \mathrm{REE}^{2+, 3+} \\
\mathrm{C}^{4+}, \mathrm{S}^{6+}, \mathrm{Si}^{4+}, \mathrm{As}^{5+}, \mathrm{V}^{5+}, \mathrm{Cr}^{6+}, \mathrm{Al}^{3+} \\
\mathrm{OH}^{-}, \mathrm{Cl}^{-}, \mathrm{CO}_{3}^{2-} \\
\mathrm{F}^{-}, \mathrm{OH}^{-}\end{array}$ & $\begin{array}{c}\mathbf{C a}^{2+} \\
\mathbf{P}^{5+} \\
\mathbf{F}^{-} \\
\mathbf{O}^{2-}\end{array}$ \\
\hline
\end{tabular}


إن معدل التتاسق في الموقعين Ca (I) و Ca (II) في بلورة الفرانكولايت هو تناسق ثماني، وحدود

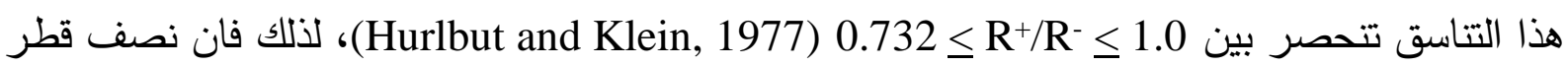

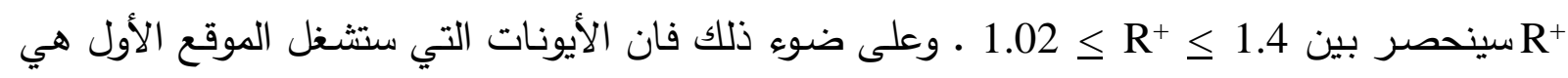

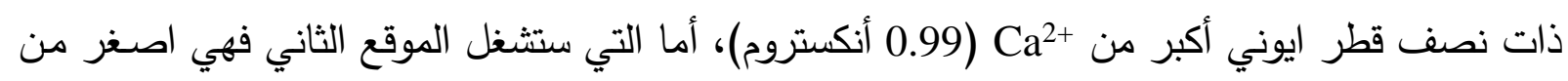

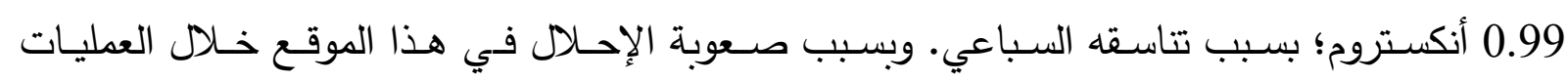
التحويريـة المبكرة والمتأخرة، لأنـه محاط بتسعة أوكسـين التابعة لمجموعة الفوسفات، فـان محتوى هذا الموقع سيمثل الأيونات الكبيرة الموروثة خلال مرحلة تكوين الفرانكولايت مثل Sr+2+ Slansky, 1986). ولهذا السبب يبدو ان الموقع الثاني للكالسيوم، هو أكثر تعرضـا للإحلال من الموقع الأول؛ بسبب التناسق السباعي من جهة ووجوده حول القناة البلوريـة للأبتايت (اليوزبكي والدباغ، 2018)، ممـا يسهل عملية التبادل الأيوني من جهة أخرى (Lanifranco et al., 2004).

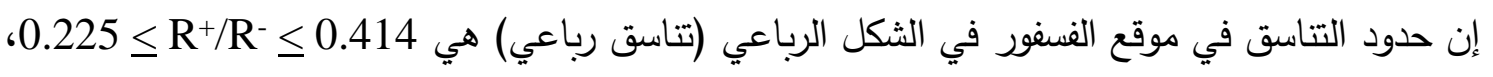

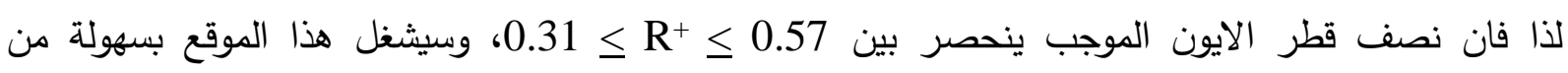
العناصر التي لها جذور رباعية مشابهة لجذر PO4 مثل $\mathrm{PO}_{4}$ ذات أنصاف أقطار ضمن المدى أعلاه، وكذلك بعض الايونات مثل Tribble, et al., 1995 and ) المدى. فضلا عن إحلال جذور الكاربونات بشكل شائع محل الفوسفات لإنهات فمountain and McClellan, 2000 ). وبالرغم من ان الدراسات المعدنية أشارت إلى وجود طور معدني فوسفاتي، واحد وهو الفرانكولايت (اليوزبكي، 2004)، إلا ان هذه الجذور من الممكن ان تحل محل الفوسفات بسهولة، ولاسيما ان نسبة الإحلال في هذا الموقع قد تصل إلى 30\%، كما هو الحال في إحلال الكاربونات

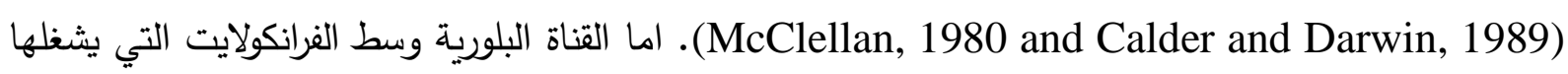
موقعان للفلور ، فان وفرة هذا العنصر ستتحكم بإحلال الأيونات السالبة (Harlov et al., 2003). ترتبط بعض ولات (Benmre et al., 1983 and Nathan, العناصر مع الفرانكولايت بهيئة ايونات ممتصة داخل القناة البلورية (1984، أو ممتزة على السطح الخارجي للمعدن؛ نتيجة الثحنة الجزيئية المتبقية على السطح بفعل الايونات الداخلة في القناة، أو ممتزة على المادة العضوية الموجودة على سطح الحبيبة أو مغلفة لها (Slansky, 1986).

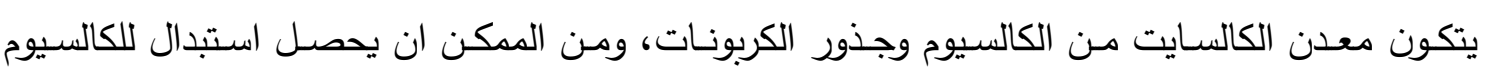

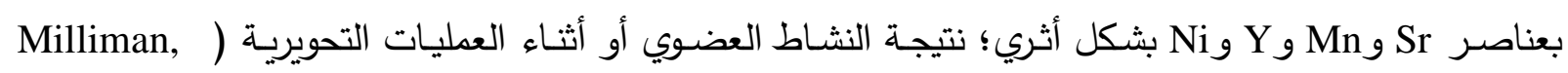

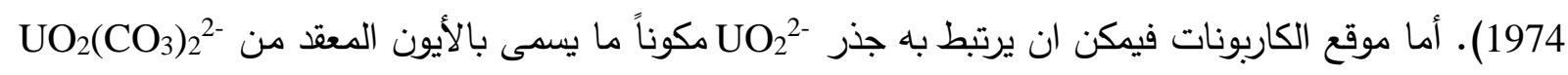
.(Krauskopf, 1985)

يتكون التركيب البلوري للمعادن الطينية بشكل عام من ارتباط طبقات رباعيات الأوجه ( tetrahedron

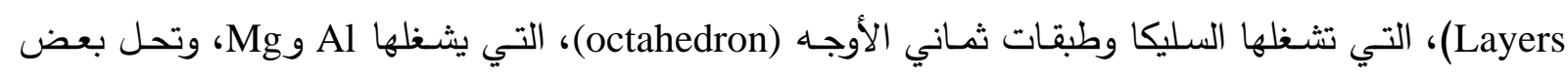

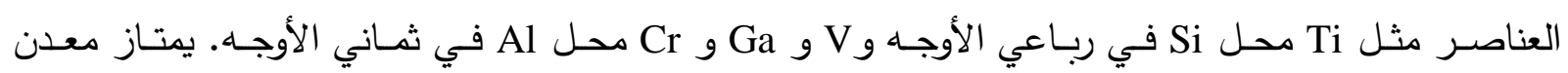


الباليكورسكايت بسبب طبيعته البلورية ذات الأقنية بإمتزاز كثير من العناصر مثل Cu و Ni و الأقنية أو على سطح حبيباته (Murray, 2002 واليوزبكي، 2004).

\section{طرائق التحليل}

تم تحليل 117 أنموذجا لصـخور خامـات مقالع عكاشـات مضـافا إليها 5 نمـاذج عظام وأنموذج أسنان.

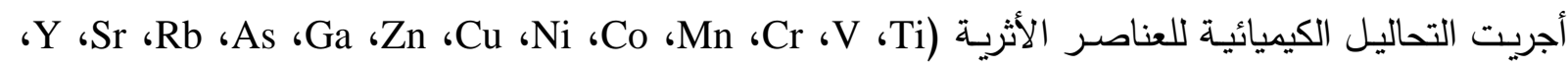

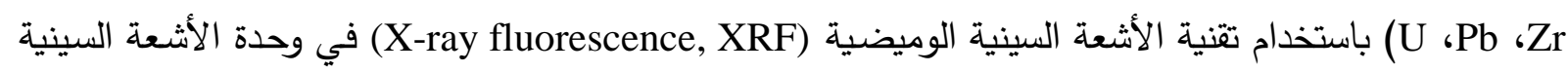
في قمم علوم الأرض، كلية العلوم، جامعة الموصل في عام 2002، وقد تم التحليل وفق الظروف المعتمدة في الوحدة (مثل نوع انبوبة الأشعة السينية والبلورة المحلة ومقدار التيار وفرق الجهد الكهربائي المستخدمين والموجه)

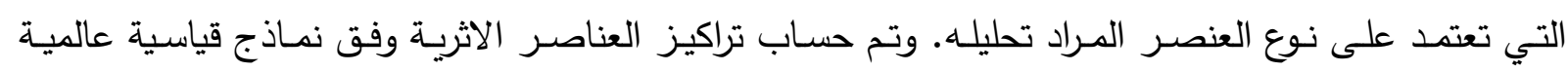
(ASK-1, SY-2, SY-3, MRG-1, BCR-1, BX-N :International standards) التحاليل الكيميائية القياسية العالمية (Sen Gupta, 1977). استخدم البرنامج الحاسوبي SPSS لغرض حساب معاملات الارتباط عند مستوى المعنويـة 0.95، وبلغت القيم المعنوية الدنيا المطلقة r=0.28 بغض النظر عن طبيعة القيم طردية كانت (+ve) او عكسية (-ve).

\section{النتائج وإلمناقشة}

\section{Geochemistry of trace elements بوكيميائية العناصر الأثرية}

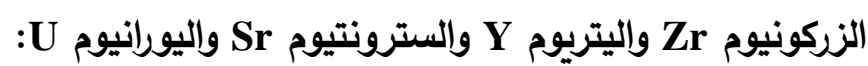
ترتبط هذه العناصر بشكل رئيس مـع الطور الفوسفاتي؛ إذ توجد عادة في الأبتايت أكثر من الكالسايت

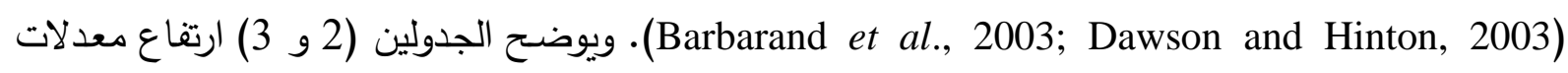
تراكيز Zr و Y و Sr و U Uي الفوسفورايت مقارنـة بالصـخور الجيريـة الفوسفاتية. إذ تتحصر بين 73 - 88 ج•م•م و 43 - 53 ج•م•م و 1175 - 1437 ج.م•م و39 - 143 - 54 ج.م.م على التوالي في الفوسفورايت. في حين

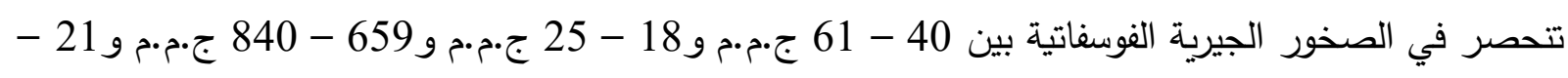
31 ج.م.م على التوالي. وكذلك الحال في نماذج الاسنان والعظام؛ إذ تكون معدلات تراكيز هذه العناصر مقاربة (أكثر قليلا) لمعدلاتها في الفوسفورايت، (الجدول 4). ويظهر ذلك واضحا عن طريق معاملات الارتباط الطردية

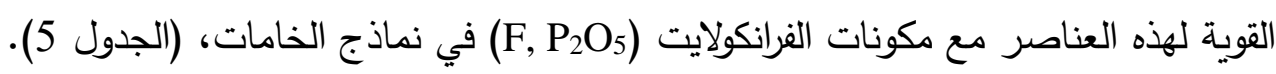
وبشكل عام يلاحظ إن معدل تركيز عنصر Zr في هذه الصخور أقل من معدل تركيزه في صخور الطفل،

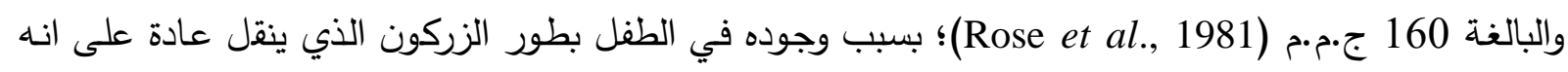

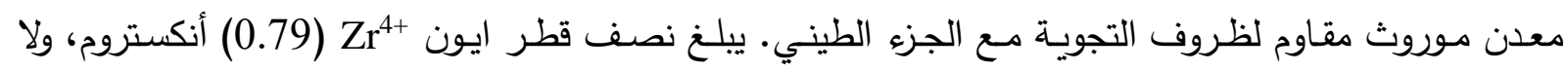

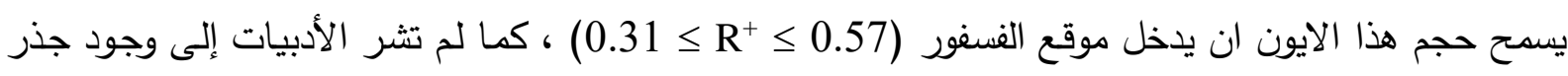
ضrO4 الفوسفات، وعلى الأخص طور Xenotime, YPO4 على حبيبات الزركون الفتاتية المنقولة الناعمة الحجم. 
جيوكيميائية الفوسفورايت والصخور المصاحبة لها ضمن تكوين عكاشات (الباليوسين الأوسط)..............

الجدول 2: تراكيز العناصر الأثرية (ج•م•م) في الفوسفورايت والصخور الفوسفاتية للمقلع الأول.

\begin{tabular}{|c|c|c|c|c|c|c|c|c|}
\hline \multicolumn{4}{|c|}{ المقلع الأول الثانوي } & \multicolumn{4}{|c|}{ المقلع الأول الرئيس } & \multirow{3}{*}{$\overline{9}$} \\
\hline \multicolumn{2}{|c|}{ الصخور الفوسفاتية } & \multicolumn{2}{|c|}{ الفوسفورايت } & \multicolumn{2}{|c|}{ الصخور الفوسفاتية } & \multicolumn{2}{|c|}{ الفوسفورايت } & \\
\hline المعدل & المدى & المعدل & المدى & المعدل & المدى & المعدل & المدى & \\
\hline 18 & $29-5$ & 23 & $37-2$ & 20 & $28-13$ & 30 & $206-1$ & As \\
\hline 1.5 & $2-1$ & 1.5 & $2-1$ & 2 & $4-0$ & 1.5 & $4-0$ & Co \\
\hline 237 & $291-133$ & 230 & $362-175$ & 222 & $276-136$ & 343 & 454-196 & $\mathrm{Cr}$ \\
\hline 21 & $37-9$ & 24 & $40-14$ & 21 & $43-10$ & 26 & $47-6$ & $\mathbf{C u}$ \\
\hline 14 & $16-11$ & 17 & $21-11$ & 9 & $15-2$ & 14 & $22-1$ & $\mathbf{G a}$ \\
\hline 68 & $106-33$ & 78 & $130-40$ & 34 & $40-24$ & 32 & $51-19$ & Mn \\
\hline 64 & $154-13$ & 54 & $93-15$ & 39 & $84-11$ & 42 & $84-3$ & $\mathbf{N i}$ \\
\hline 44 & $100-1$ & 58 & $104-11$ & 13 & $71-0$ & 27 & $128-0$ & $\mathbf{P b}$ \\
\hline 2 & $3-1$ & 1.67 & $2.2-1.1$ & 2.5 & $3-2$ & 3 & $73-1$ & $\mathbf{R b}$ \\
\hline 840 & $1385-332$ & 1437 & $1836-1230$ & 659 & $962-389$ & 1314 & $1686-949$ & $\mathbf{S r}$ \\
\hline 353 & $857-153$ & 224 & $397-167$ & 243 & $333-147$ & 230 & $394-131$ & $\mathbf{T i}$ \\
\hline 23 & $38-9$ & 39 & $64-27$ & 24 & $49-13$ & 46 & $96-30$ & $\mathbf{U}$ \\
\hline 72 & $88-51$ & 74 & $170-17$ & 46 & $104-0$ & 103 & $202-21$ & $\mathbf{V}$ \\
\hline 25 & $38-1$ & 43 & $108-23$ & 18 & $36-0$ & 53 & $104-24$ & $\mathbf{Y}$ \\
\hline 617 & $1295-353$ & 514 & $845-251$ & 529 & $779-293$ & 535 & $791-143$ & $\mathbf{Z n}$ \\
\hline 61 & $86-36$ & 88 & $114-72$ & 52 & $63-35$ & 83 & $102-60$ & $\mathbf{Z r}$ \\
\hline
\end{tabular}

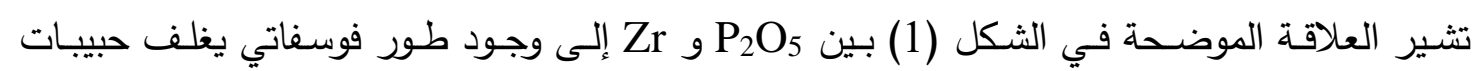
الزركون، أو ربما تعزى الى تكوين طور YrP (Yamanaka and Kaizumi, 1975). وبسبب انخفاض تركيز كل من Zr و Yr لم تظهر هذه الأطوار أثناء التحاليل المعدنية بالأشعة السينية الحائدة لمعدن الفرانكولايت في فوسفورايت تكوين عكاشات (الشكل 2). 


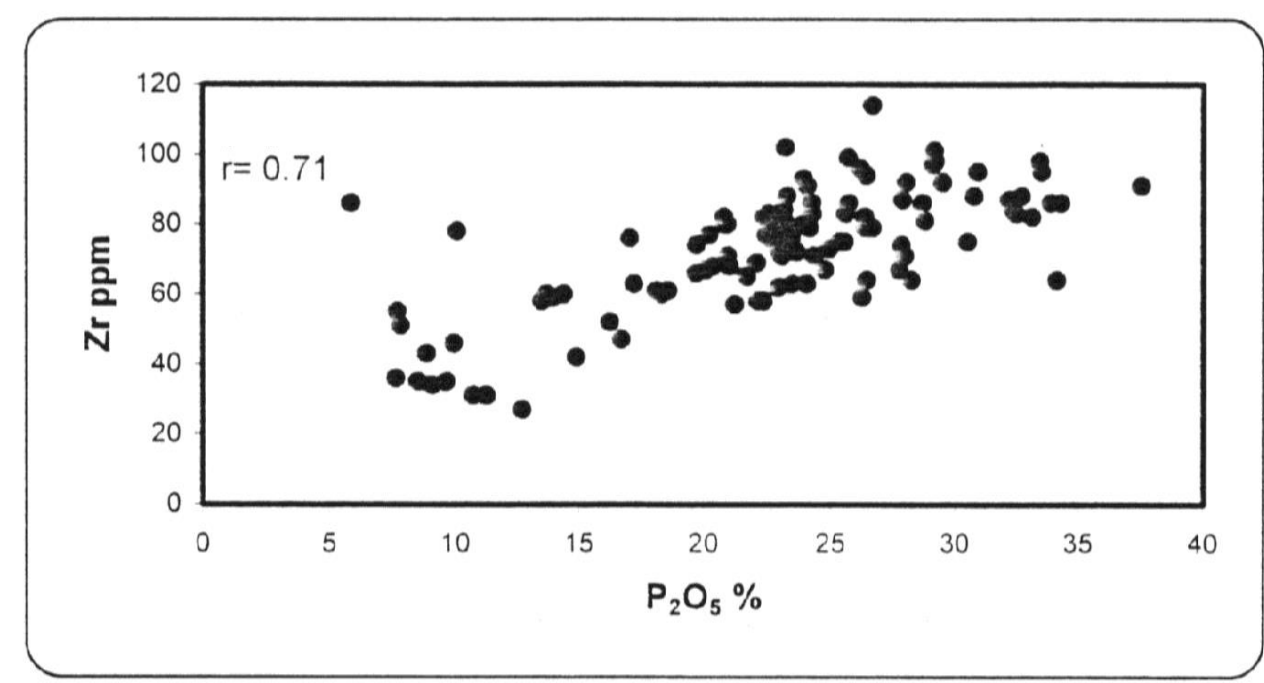

الثكل 1: ارتباط Zr مع الفرانكولايت بشكل رئيسي.

الجدول 3: تراكيز العناصر الأثرية (ج·م.م) في الفوسفورايت والصخور الفوسفاتية للدقلع الثاني.

\begin{tabular}{|c|c|c|c|c|c|c|c|c|}
\hline \multicolumn{4}{|c|}{ المقلع الثاني 1994} & \multicolumn{4}{|c|}{ المقلع الثاني 2001} & \multirow{3}{*}{ 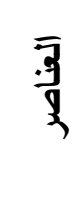 } \\
\hline \multicolumn{2}{|c|}{ الصخور الفوسفاتية } & \multicolumn{2}{|c|}{ الفوبفورايت } & \multicolumn{2}{|c|}{ الصخور الفوسفاتية } & \multicolumn{2}{|c|}{ الفوسفورايت } & \\
\hline المعدل & المدى الم & المعدل & المدى الم & المعدل & المدى & المعدل & المدى الم & \\
\hline 6 & $16-0$ & 16 & $29-0$ & 12 & $20-0$ & 13 & $31-0$ & As \\
\hline 1 & $3-0$ & 1 & $2-1$ & 1 & $2-1$ & 1 & $2-0$ & Co \\
\hline 248 & $294-185$ & 295 & $351-234$ & 218 & $257-187$ & 335 & $434-243$ & $\mathrm{Cr}$ \\
\hline 24 & $25-22$ & 24 & $30-14$ & 17 & $23-1$ & 21 & $34-0$ & $\mathbf{C u}$ \\
\hline 13 & $18-8$ & 15 & $23-7$ & 15 & $19-12$ & 15 & $20-10$ & Ga \\
\hline 73 & $100-57$ & 102 & $267-58$ & 30 & $38-25$ & 35 & $56-25$ & Mn \\
\hline 25 & $33-13$ & 31 & $61-5$ & 26 & $44-1$ & 28 & $95-0$ & $\mathbf{N i}$ \\
\hline 71 & $75-65$ & 78 & $111-29$ & 31 & $56-0$ & 36 & $95-0$ & $\mathbf{P b}$ \\
\hline 2 & $3-2$ & 2 & $3-1$ & 3 & $4-2$ & 3 & $4-1$ & $\mathbf{R b}$ \\
\hline 767 & $970-445$ & 1175 & $1445-850$ & 662 & $1333-54$ & 1226 & $1671-771$ & $\mathbf{S r}$ \\
\hline 172 & $211-136$ & 179 & $238-150$ & 151 & $192-97$ & 196 & $302-139$ & $\mathbf{T i}$ \\
\hline 21 & $32-11$ & 41 & $107-28$ & 31 & $40-12$ & 54 & $57-31$ & $\mathbf{U}$ \\
\hline 49 & $93-19$ & 59 & $103-0$ & 21 & $88-0$ & 85 & $152-6$ & $\mathbf{V}$ \\
\hline 22 & $40-0$ & 43 & $101-14$ & 22 & $46-2$ & 50 & $92-14$ & $\mathbf{Y}$ \\
\hline 448 & $632-355$ & 447 & $679-344$ & 392 & $682-188$ & 503 & $789-220$ & $\mathbf{Z n}$ \\
\hline 53 & $66-35$ & 76 & $97-58$ & 40 & $76-27$ & 73 & $98-57$ & $\mathbf{Z r}$ \\
\hline
\end{tabular}


Al- يعد اليتريـوم مـن العناصـر الفقيـرة في فوسفورايت الباليوسـين مقارنـة بفوسفورايت الـدول المجـاورة

Bassam et al., 1990 . يحل اليتريوم محل الكالسيوم في الكالسايت والفرانكولايت؛ بسبب التشابه بين أنصاف بعاف

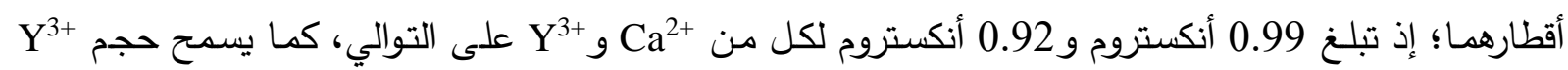
إشغال الموقعين Ca(I) و Ca (II) في بلورة الفرانكولايت، ويعتقد ان Y يشغل الموقع Ca(I) الذي يعكس مرحلة تكوين الفرانكولايت من المياه البينية في المناطق العميقة أكثر من إشغال الموقع (II) Ca (الذي يعكس عملية Altschuler, ) الإحلال والتبادل الأيوني أثناء المراحل التحويرية؛ وذلك لقرب هذا الموقع من سطح القناة الداخلي التئي

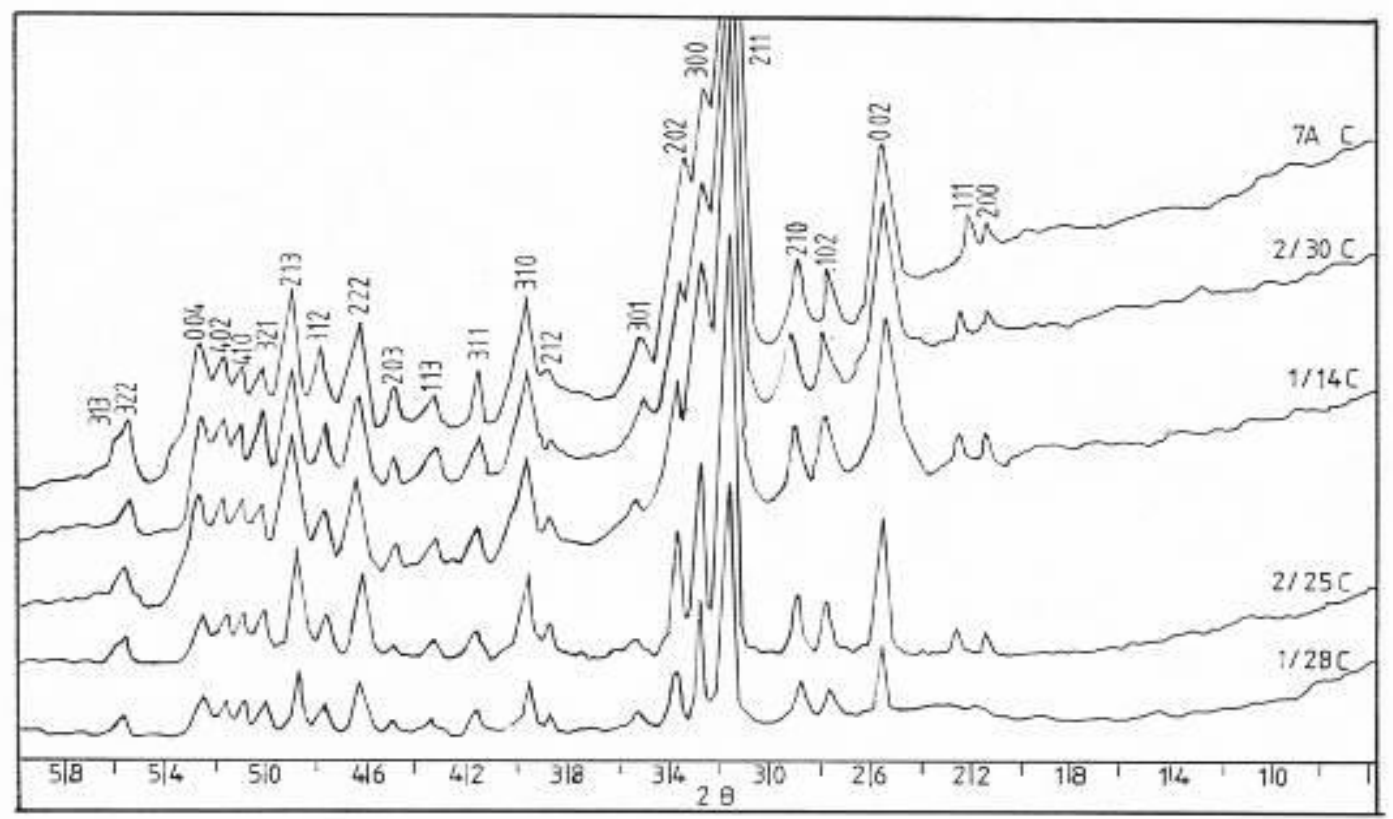

الثكل 2: مخطط الأشعة السينية الحائدة لمعدن الفرانكولايت في فوسفورايت تكوين عكاشات

الجدول 4: تراكيز العناصر الأثرية (ppm) في نماذج الأسنان والعظام.

\begin{tabular}{|c|c|c|c|c|c|}
\hline المعدل & المسىى & العناصر الأثرية & المعدل & المـدى & العناصر الأثرية \\
\hline 3 & $3-2$ & $\mathbf{R b}$ & 30 & $37-9$ & As \\
\hline 1381 & $1581-988$ & $\mathrm{Sr}$ & 2 & $3-1$ & Co \\
\hline 91 & $107-76$ & Ti & 132 & $158-122$ & $\mathrm{Cr}$ \\
\hline 88 & $197-30$ & $\mathbf{U}$ & 22 & $28-18$ & $\mathbf{C u}$ \\
\hline 48 & $98-29$ & $\mathbf{V}$ & 14 & $17-10$ & $\mathbf{G a}$ \\
\hline 23 & $40-0$ & $\mathbf{Y}$ & 37 & $42-30$ & Mn \\
\hline 268 & $350-178$ & Zn & 0 & $0-0$ & $\mathbf{N i}$ \\
\hline 89 & $98-64$ & $\mathbf{Z r}$ & 16 & $25-0$ & $\mathbf{P b}$ \\
\hline
\end{tabular}


وعلى الرغم من علاقة الإحلال هذه، إلا إن معامل الارتباط بين CaO و في مجموعة الخامات يشير إلى علاقة غير معنوية، وربما يعزى ذلك إلى تباين محتوى الفرانكولايت والكالسايت من اليتريوم، كما يظهر من الجدولين (2 و 3) ارتفاع معدلات تراكيز Y في الفوسفورايت مقارنة مع الصخور الجيريـة الفوسفاتية. أما علاقة مع Y P احلال اليتريوم في معدن الفرانكولايت، إذ يزداد الاحلال محل الكالسيوم في الموقع Ca(I) مع زيادة Pa مراحل التكوين المبكرة، والثاني: يمثل محتوى معدن الفرانكولايت من اليتريوم خـلال العمليات التحويريـة إذ يحل

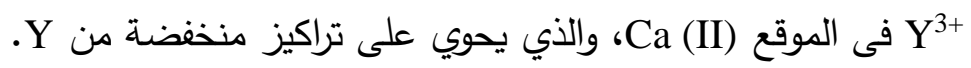

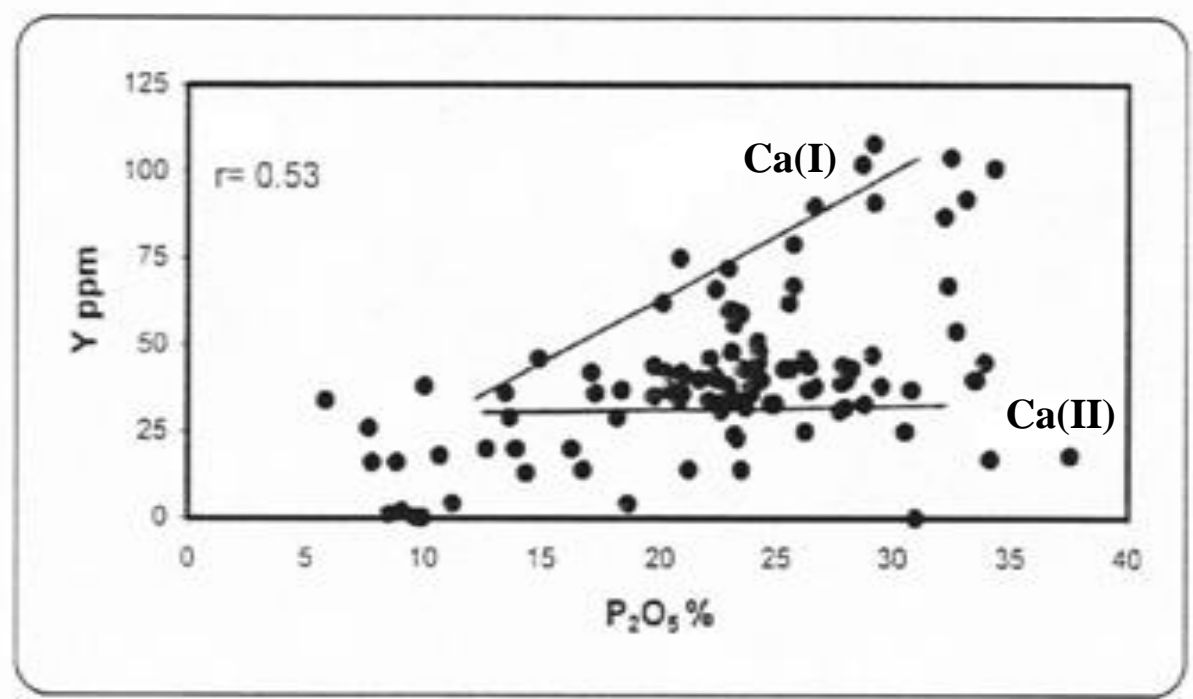

الثكل 3: علاقة اليتريوم مع معدن الفرانكولايت.

يعد عنصـر Sr أكثر العناصـر الأثريـة اغتـاءاً في الفوسفورايت (1175 - 1437) ج•م·م مقارنـة مـع

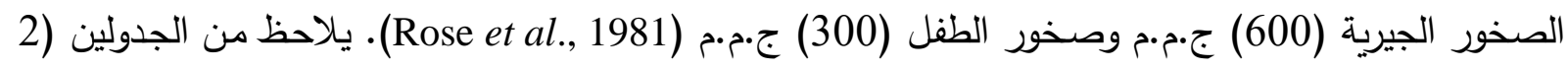
و3) ارتفاع تراكيز Sr في الفوسفورايت، كما أشار إلى ذلك (Al-Bassam, 1992). ويشير نصف قطره الأيوني الكبير والبالغ 1.12 أنكستروم الى احتلال السترونتيوم الموقع Ca(I) في بلورة الفرانكولايت (Slansky, 1986).

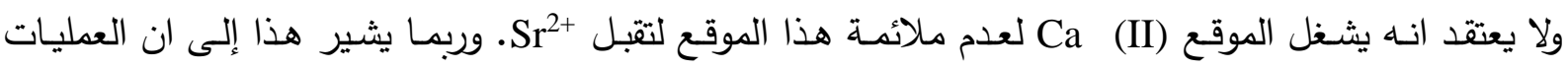
التحويريـة التي تحدث لاحقا لا تؤثر على محتوى الفوسفورايت من Sr (اليوزبكي والدباغ، 2018). يعتقد بـان تكوين او نشأة الفرانكولايت تتم عن طريق فسفتة الأراكونايت (Jarvis, 1980) الموجود في الوحل الكربوناتي، وهو الطور المعدني الذي تتكون منه قثور وأصداف اغلب الأحياء البحرية (Prevot-Lucas and Lucas, 1980) هذانيات من جهة، واغتتاء الأراكونايت بـ Sr بسبب نظامه البلوري المعيني القائم الذي يسمح بـخول Sr Sr أكثر من دخوله

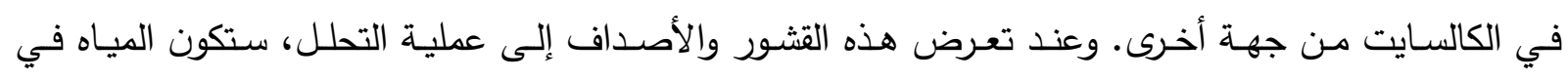

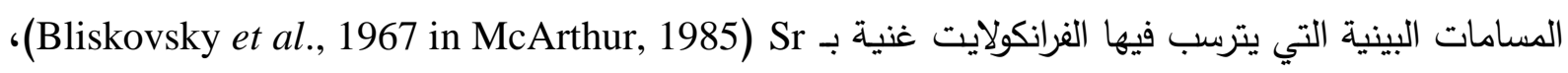

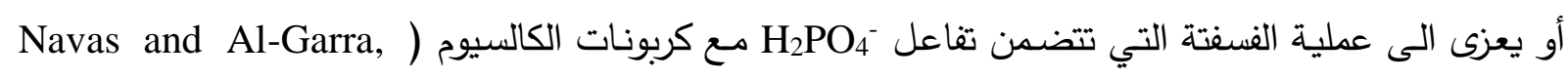


2001)، ولا يتأثر محتوى Sr بهذه العملية (Prevot-Lucas and Lucas, 1980)، ولذلك فان محتواه سيبقى موروثا في الفرانكولايت (اليوزبكي والدباغ، 2018) (الشكل 4).

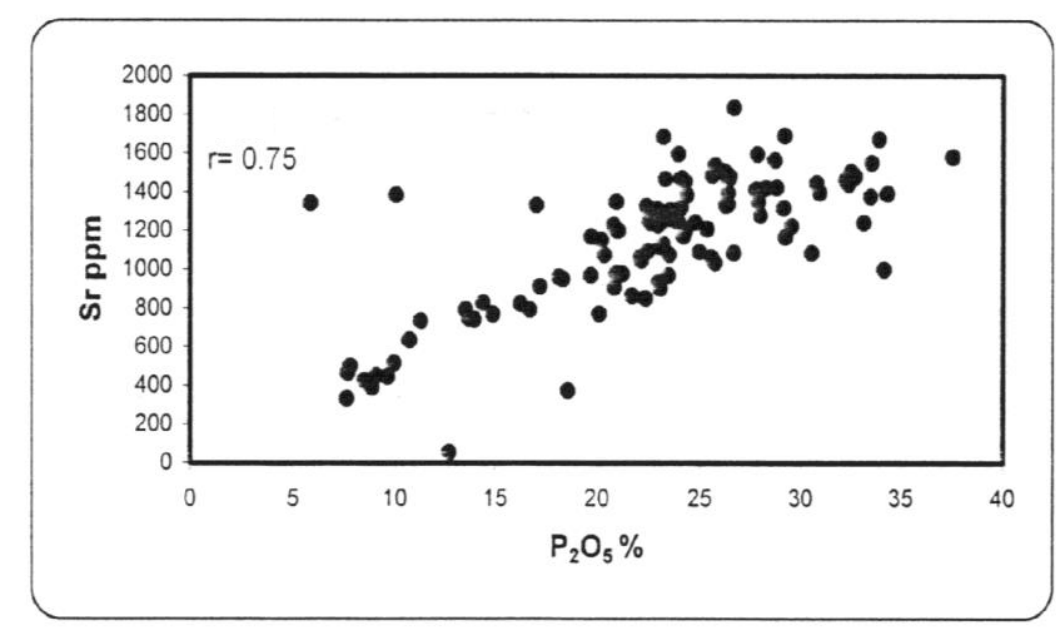

الشكل 4: ارتباط Sr مع الفرانكولايت بشكل رئيس.

الجدول 5: معاملات الارتباط في نماذج الخامات (N = 123)

\begin{tabular}{|l|c|c|c|c|c|c|c|c|c|c|c|c|}
\hline & $\mathbf{T i}$ & $\mathbf{Z r}$ & $\mathbf{Y}$ & $\mathbf{S r}$ & $\mathbf{U}$ & $\mathbf{Z n}$ & $\mathbf{C u}$ & $\mathbf{N i}$ & $\mathbf{M n}$ & $\mathbf{C r}$ & $\mathbf{V}$ & $\mathbf{P b}$ \\
\hline $\mathbf{C a O}$ & - & -.38 & - & - & - & - & - & - & - & - & - & - \\
\hline $\mathbf{S i O}_{2}$ & 0.86 & - & - & - & - & 0.64 & 0.32 & 0.72 & - & - & - & - \\
\hline $\mathbf{A l}_{2} \mathbf{O}_{3}$ & 0.52 & - & - & - & - & 0.47 & - & 0.51 & - & - & - & - \\
\hline $\mathbf{F e}_{2} \mathbf{O}_{3}$ & 0.85 & - & - & - & - & 0.61 & 0.32 & 0.72 & - & - & - & - \\
\hline $\mathbf{M g O}_{\mathbf{O} O}$ & 0.37 & - & -.28 & - & -.30 & 0.36 & - & 0.39 & - & - & - & - \\
\hline $\mathbf{K}_{2} \mathbf{O}$ & 0.79 & - & - & - & - & 0.62 & 0.30 & 0.59 & - & 0.36 & - & - \\
\hline $\mathbf{N a}_{2} \mathbf{O}$ & - & - & - & - & - & 0.29 & - & - & - & - & - & - \\
\hline $\mathbf{S O}_{3}$ & - & 0.77 & 0.42 & 0.85 & 0.56 & - & 0.29 & - & - & - & - & - \\
\hline $\mathbf{P}_{2} \mathbf{O}_{5}$ & - & 0.71 & 0.53 & 0.75 & 0.68 & - & - & - & - & 0.33 & 0.30 & - \\
\hline $\mathbf{F}$ & - & 0.65 & 0.51 & 0.64 & 0.52 & - & - & - & - & - & - & - \\
\hline $\mathbf{C l}_{\mathbf{C l}}$ & 0.29 & - & - & - & - & - & - & 0.34 & - & - & - & - \\
\hline $\mathbf{C O} \mathbf{O}_{2}$ & - & -.57 & - & -.63 & -.62 & - & - & - & - & - & - & - \\
\hline $\mathbf{C}$ org. & - & - & - & - & 0.41 & - & - & - & - & - & - & - \\
\hline $\mathbf{H}_{2} \mathbf{O}^{+}$ & - & 0.38 & 0.28 & 0.34 & 0.29 & - & - & - & - & 0.46 & - & - \\
\hline $\mathbf{T i}$ & 1 & - & - & - & - & 0.70 & 0.31 & 0.76 & - & 0.44 & - & - \\
\hline $\mathbf{Z r}$ & & 1 & 0.55 & 0.84 & 0.53 & - & - & - & - & 0.36 & 0.35 & - \\
\hline $\mathbf{Y}$ & & & 1 & 0.48 & 0.47 & - & - & - & - & 0.46 & 0.40 & - \\
\hline $\mathbf{S r}$ & & & & 1 & 0.62 & - & - & - & - & 0.34 & - & - \\
\hline $\mathbf{R b}$ & & & & & & - & - & - & -.40 & - & - & - \\
\hline $\mathbf{Z n}$ & & & & & & 1 & 0.53 & 0.83 & - & 0.49 & - & - \\
\hline $\mathbf{C u}$ & & & & & & & 1 & 0.46 & - & 0.35 & 0.30 & - \\
\hline $\mathbf{N i}$ & & & & & & & & 1 & - & 0.39 & - & - \\
\hline $\mathbf{M n}$ & & & & & & & & & 1 & - & - & 0.46 \\
\hline $\mathbf{C r}$ & & & & & & & & & & 1 & 0.43 & - \\
\hline
\end{tabular}




\begin{tabular}{|l|l|l|l|l|l|l|l|l|l|l|l|c|}
\hline $\mathbf{V}$ & & & & & & & & & & & 1 & - \\
\hline $\mathbf{G a}$ & & & & & & & & & & & & 0.33 \\
\hline Pb & & & & & & & & & & & & 1 \\
\hline
\end{tabular}

يتوزع Uين عدة أطوار : في الفرانكولايت (Altschuler et al., 1958 and Jerden, 2003)، والكالسايت

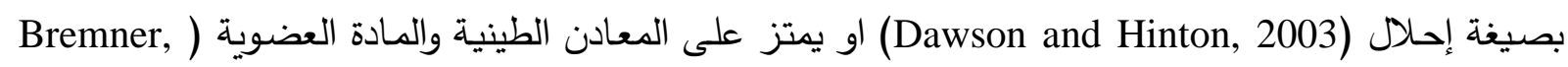
1980). إلا إن أكثر تركيز لا U يكون في الفرانكولايت؛ إذ يعد الأخير أحد مصـادر اليورانيوم، فضـلا عن وجوده في مجموعـة معـادن الكارنوتايـت مثـل اوتونايـت Autunite وتيويامونايـت tyuyamunite وميتاتيويامونايــت Dall Aglio ) U وهي أطوار ثانوية تتكون نتيجة تجوية المعادن الفوسفاتية المحتوية على (Metatyuyamunite ف فوسفورايت عكاشات (محمد، 1985 وأبا حسين، 1987). كما لوحظ ايضـا في المشاهدات الحقلية في الدراسـة الحالية وجود صبغة صفراء براقة على سطوح التثققات والتكسرات في الصخور الجيريـة الفوسفاتية والفوسفورايت التي تمثل أحد معادن الكارنوتايت.

Nath et al., 2000 and ) ومازال الأسـاس النظري للإحلال البلوري لليورانيوم غير واضح لحد الانس

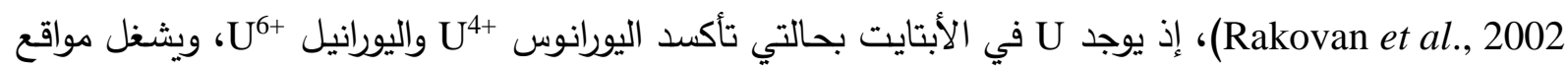

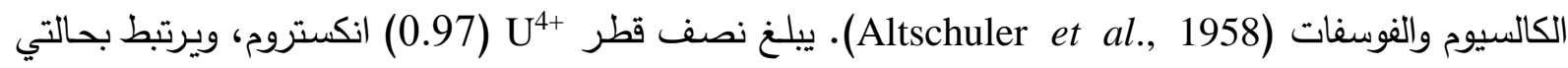
تتاسق ثمانية وسداسية ولذلك من الممكن ان يحتل موقع Ca (I) وهو بذلك يخالف شروط الإحـال في تقارب الشحنة بين ايوني الإحلال (فرق شحنة واحدة فقط)، إلا ان حالة التتاسق للموقع هي التي تسمح بحصول مثل

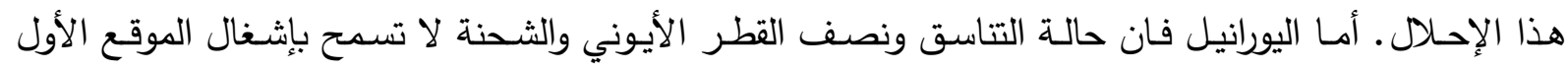

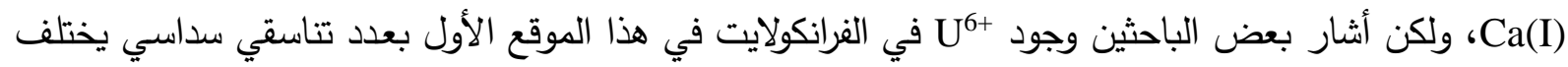
عن عدد التناسق التساعي لهذا الموقع (Rakovan et al., 2002). ولعل الرأي الذي طرحه ( Altschuler et al.,

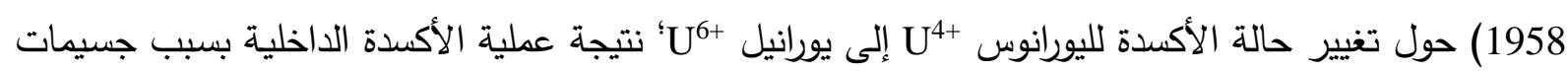

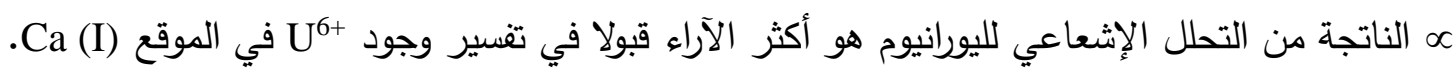

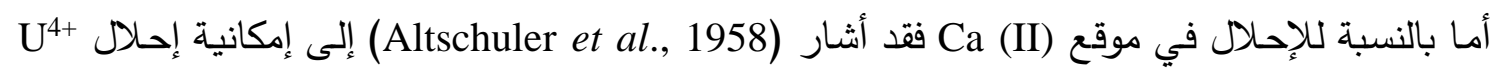

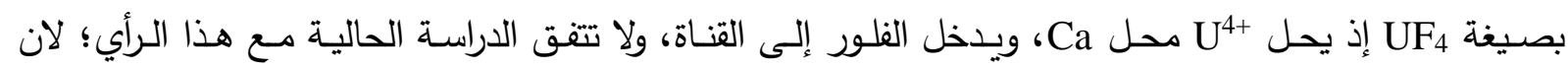

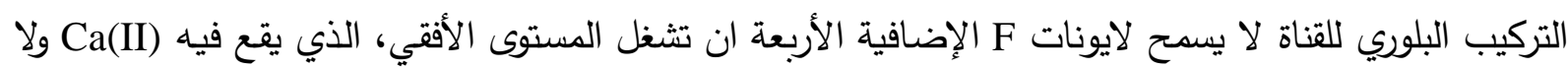
حتى المسافة العمودية على طول القناة لوجود مواقع مشغولة بالفلور • ان نصف قطر أيون اليورانيل يشابه حجم

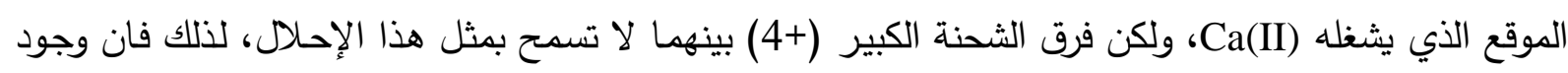
يكون عادة بشكل إمتزاز على الأسطح الداخلية (داخل القناة) في بلورة الفرانكولايت. ويعتقد ان هذه الحالة لئل

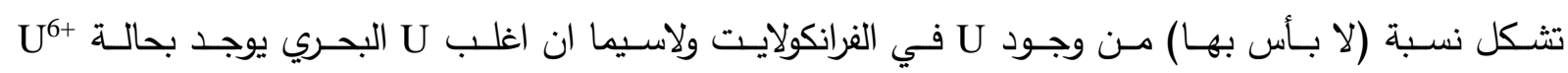
.(Altschuler, 1980)

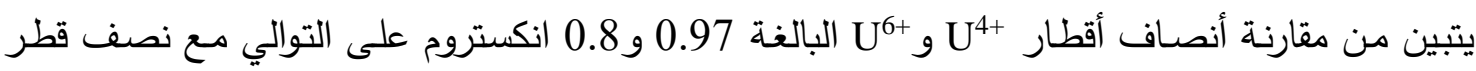

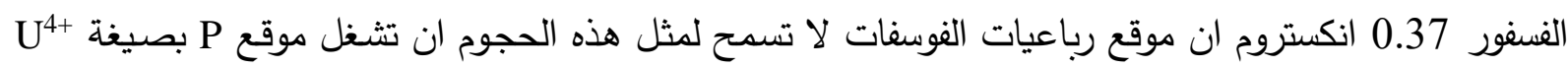

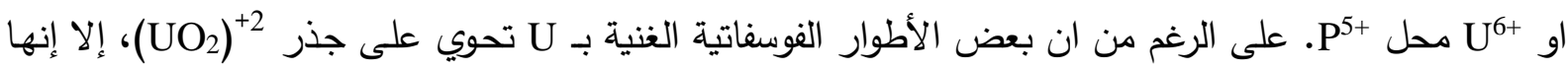


تتبع أنظمـة بلوريـة (اغلبها أحاديـة الميل) تختلف عن النظـام السداسـي للأبتايت، ولذلك يتوقع ان حالة إحـلال

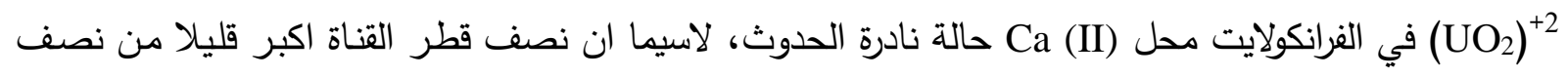

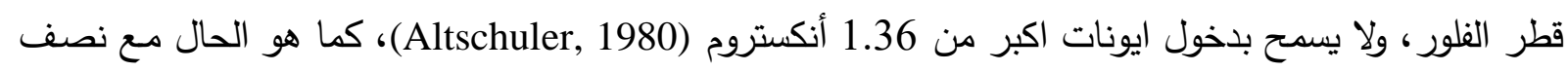

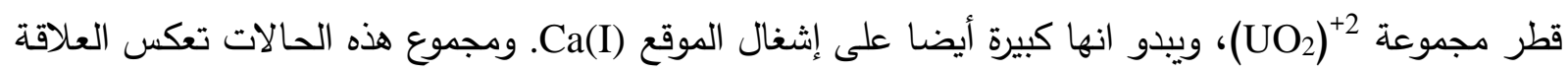

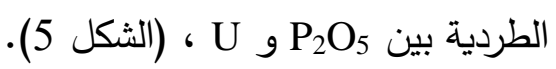

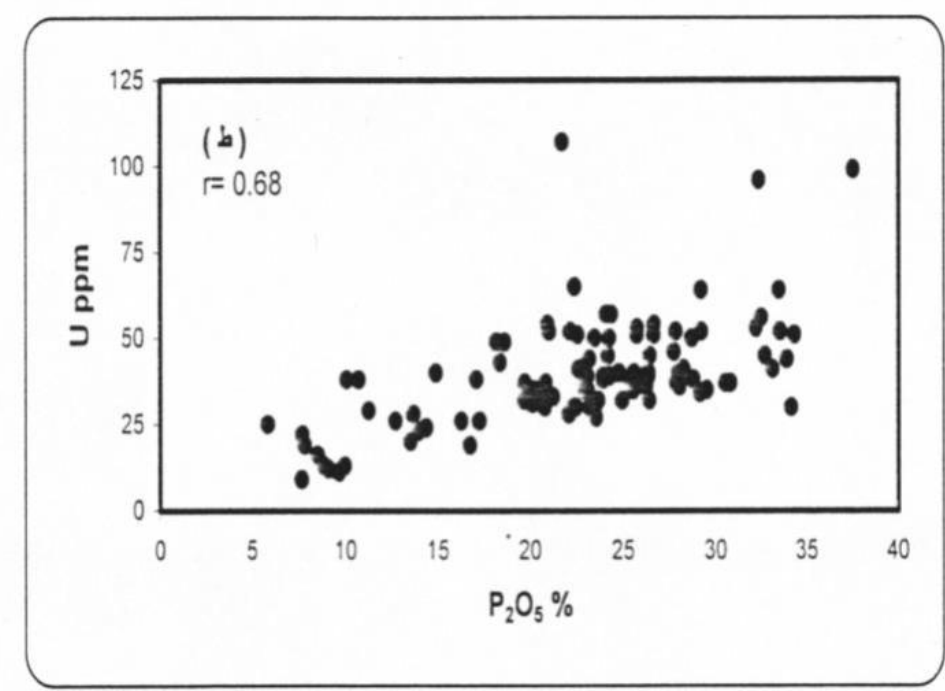

الثكل 5: ارتباط U مع الفرانكولايت بشكل رئيس..

تلعب المادة العضوية دورا كبيرا في ترسيب U في الأبتايت، إذ يحصل اختزال لليورانيل إلى اليورانوس،

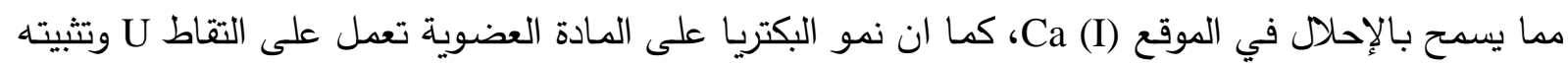
وتركيزه بشكل مدتز على سطح هذه الحبيبات، كما أشـار (Al-Dabbagh, 1989) عن طريق تحليل مسارات الانفـلاق (fission track) لليورانيوم في فوسفورايت الباليوسين (عكاشـات) ان بعضـها تتركز حول الحبيبات الفوسفاتية، وهي تعكس تجمع U على المادة العضوية المغلفة لهذه الحبيبات. يتوزع U في الأطوار المصاحبة للفرانكولايت أيضا، إذ يحل محل Ca في الكالسايت، ويمتز على أسطح المعادن الطينية، وعادة يكون امتزازه بهيئة

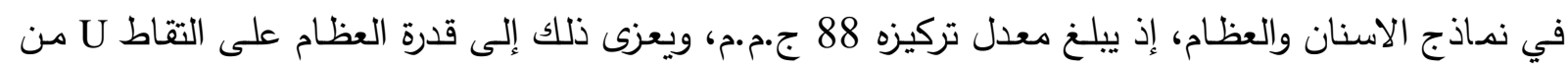
المياه (Al-Dabbagh, 1989)، وتثبيته بشكل ممتز على سطح المعدن الفوسفاتي.

الكروم Cr

يتوزع هذان العنصران بين الفرانكولايت والمعادن الطينية، ولكنهما يرتبطان بالفرانكولايت في حالة غياب

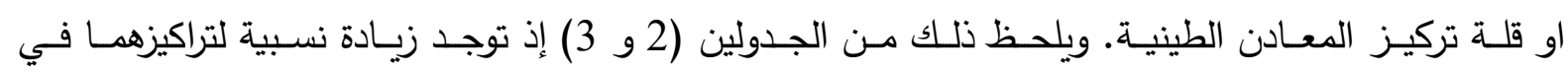
الفوسفورايت مقارنة بالصخور الجيرية الفوسفاتية، كما توضح معاملات الارتباط في نماذج الخامات ( 0.33 = ول و ارتباطهما مع الفرانكولايت أكثر من مجموعة عناصر المعادن الطينية، (الشكل 6revot-Lucas and Lucas, ) و ويحصل إمتزاز لهما على المادة العضوية المحيطة بالحبيبات الفوسفاتية 
قتان تباين النظام البلوري لمجموعة معادن VOstov, 1968) (أحادي الميل - معيني قائم) (Kos)، فان نسبة إحلال ليست كبيرة، لذلك نجد تراكيز VO بشكل عام منخفضـة في الفوسفورايت مقارنة مـع صخور

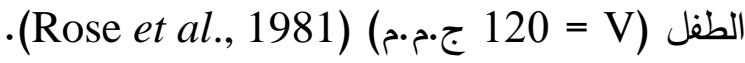

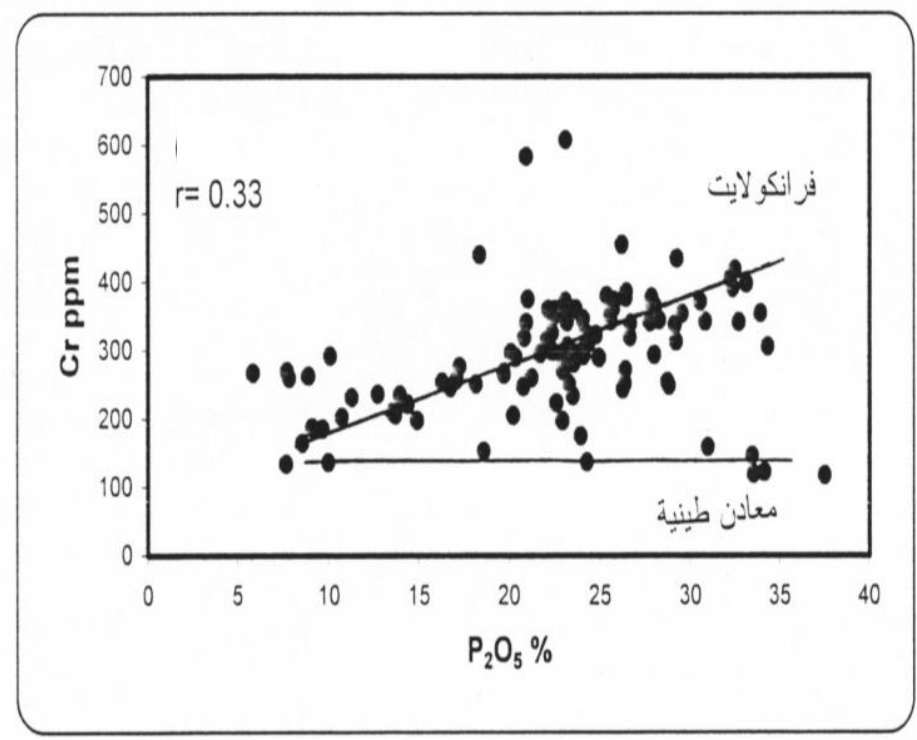

الثكل 6: علاقة Cr مع الفوسفات في الفرانكولايت.

Ca $0.63=$ Cr $^{3+}$ انكستروم و 0.74 انكستروم تسمح لها بإشغال الموقع والإمتزاز على الأسطح الداخلية للقناة البلوريـة. يوجد V و Cr أيضا في المعادن الطينية بشكل إحلال محل الألمنيوم والحديد في الطبقة الثمانية (octahedron) (Krauskopf, 1985)، كما يحصل لها إمتزاز على أسطح المعادن الطينية، إذ تكون عملية الإمتزاز للايونات الموجبة العالية الثحنة أفضل من الصغيرة الثحنة. ويلحظ من الجدول (4) إن معدل تركيز Cr و Vr في نماذج الاسنان والعظام والبالغة 132 ج.م.م و48 ج.م.م على التوالي يثير إلى وجودهما في التركيب البلوري للفرانكولايت.

التيتانيوم Ti والربايوم Rb والكاليوم Ga: ترتبط هذه العناصـر بالطور المعدني الطيني إذ يحل Ti محل Si وRb محل Ki وGa محل Al في التركيب البلوري للمعدن الطيني (Millott, 1970). ويلحظ من الجدولين (2 و 3) عدم وجود تباين كبير في محتوى الفوسفورايت والصخور الجيرية الفوسفاتية في هذه العناصر ، وبشكل خاص ضمن المقطع الواحد، مما يدل أيضا على ارتباطها بالمعادن الطينية. ويلحظ من الجدول (5) علاقة قوية بين التيتانيوم والسليكا تشير إلى احلال محل Si Ti بالنسبة لعنصر Rb فان تراكيزه المنخفضة جدا تعود إلى انخفاض تركيز اوكسيد البوتاسيوم في النماذج الذي عادةً ما يرتبط به، ويحل محله في اغلب المعادن ومنها المعادن الطينية. 
Van Olphen and Veniale, ) توجد هذه العناصر عادة بصورة ممتزة على أسطح المعادن الطينية 1981) والمـادة العضـوية (Altschuler, 1980)، التي تكون مصـاحبة للفوسفورايت. ويلحظ تقـارب معدلات تراكيزها بين الفوسفورايت والصخور الجيرية الفوسفاتية في المقطع الواحد بشكل خاص، وكذلك بين بقية المقاطع

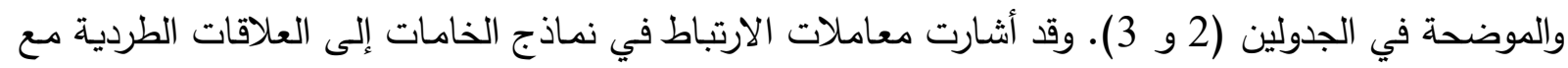
السليكا والألومينا (الجدول 5). يبين الجدول (4) معدل تركيز Zn و Cu في نماذج الاسنان والعظام إذ يبلغ 268 ج·م·م و 22 ج•م•م على التوالي، وهي تعكس استضافة الفرانكولايت للعنصرين كليهما.

المنفتيز Mn:

Stephan and ) بين الأطوار المعدنية المكونة للفوسفورايت والصـور الجيريـة الفوسفاتية

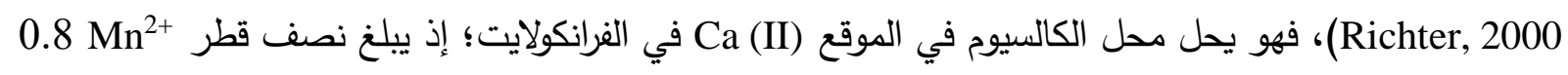

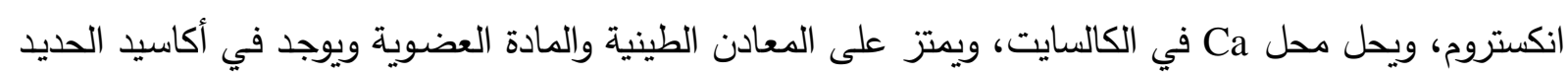
الحرة (Barbarand et al., 2003 and Dawson and Hinton, 2003)، ولذلك لا تظهر علاقات ارتباط لهذا العنصر بشكل واضـح مـع أي عنصر من العناصر الأخرى، كما ان معدلات تركيزه في الفوسفورايت والصخور الجيريـة الفوسفاتية متقاربة، في حين تتباين من موقع إلى اخر ، الجدولين (2 و 3) وربما يعزى هذا التشابه في

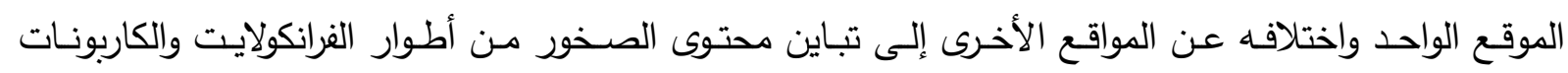
والمعادن الطينية والمواد العضوية وأكاسيد الحديد الحرة.

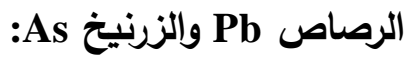

يوجد هذان العنصران في الفوسفورايت أكثر نسبيا من الصخور الجيريـة الفوسفاتية، ويتباين محتواهما من مقطع إلى آخر ، الجدولين (2 و3)، وربما يعود إلى تباين تركيز المادة العضوية، التي تمتزها وتباين توزيعهما في الأطوار المعدنية. وعلى الرغم من الألفة الجالكوفيلية لهما فان تباين هذا التوزيع لم يظهر علاقة ارتباط بئل بينهما.

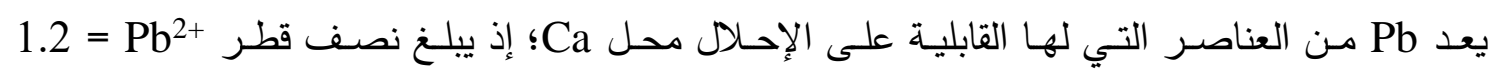
أنكستروم ، ولكنه يفضل طور الأبتايت أكثر من الكالسايت (Dawson and Hinton, 2003)، ولذلك يتوقع إن

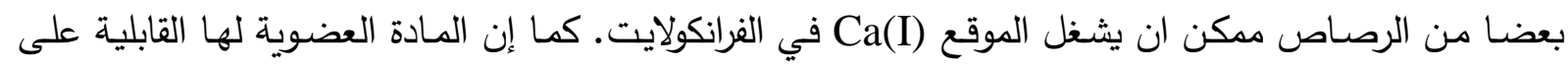

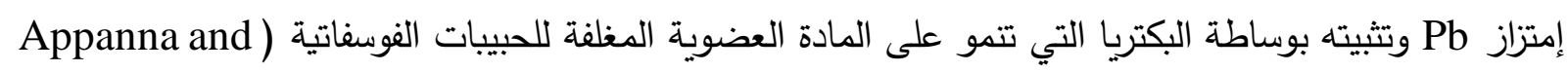
.(Hamel, 1999

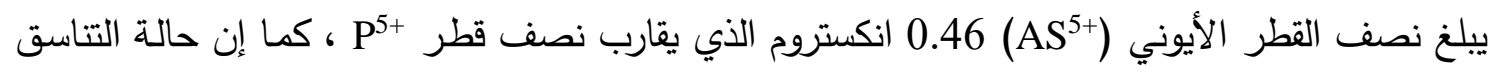

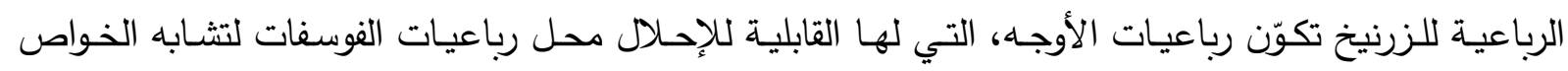

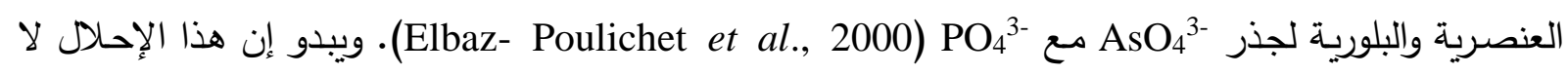
يرتبط مع الفرانكولايت فقط، بل يرتبط مع طور معدني منفصل؛ كما يتضح ذلك من معاملات الارتباط الثنائية غير المعنوية (0.09)، وبسبب انخفاض تركيز هذا الطور لم يتم تحسسه أثناء التحاليل المعدنية. وتسهم المادة العضـوية أيضـا في إمتزاز وتثبيت As (Altschuler, 1980)، ويعكس هذا الإمتزاز الدالـة الحمضـية للبيئة 


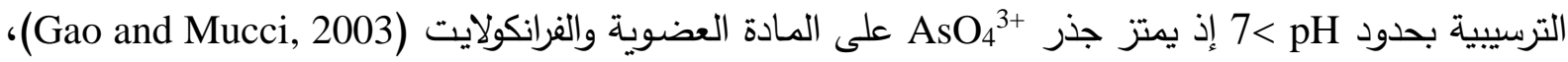
ولذلك يتباين تركيز As من مقطع لأخر تبعا لتباين تأثير العوامل المذكورة أعلاه. يثير الجدول (4) إلى إن معدل التركيز المنخفض للرصاص (16 ج.م.م) في نماذج الاسنان، ربما يعزى إلى تأثير المـادة العضوية فقط. ان معدل تركيز As (30 ج.م.م) في نماذج الاسنان الذي يقارب تركيزه في الفوسفورايت يعزى إلى وجوده بطور معدني منفصل فضلا عن امتزازه على المادة العضوية. الأستنتاجات

إن توزيع العناصر الأثرية في الفوسفوريت لا تتحكم فيه عملية الإحلال في التركيب البلوري للفرانكولايت فقط، بل كذلك وجود الأطوار المعدنية الأخرى المصاحبة ووجود المادة العضوية التي تثير إلى النشاط الإحيائي؛

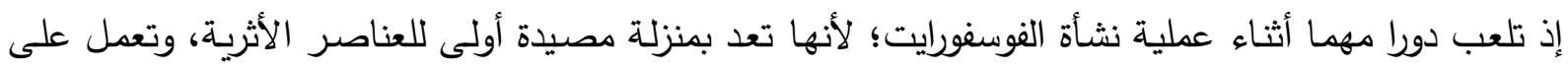
تثبيتها، ثم تؤثر العمليات البايوكيميائية فيها فتركز بعضاً منها في الفوسفورايت.

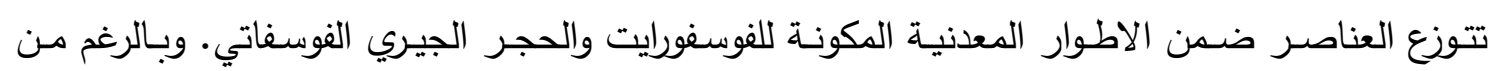
انخفاض نسبة كل من المعادن الطينية والمادة العضوية؛ الا انها تؤثر في هذا التوزيع. تمثل عناصر P و F و

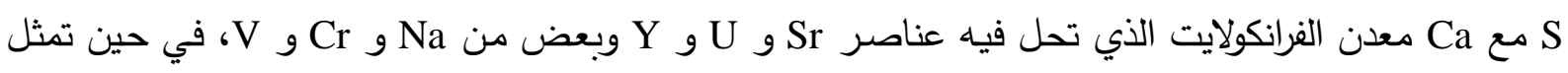

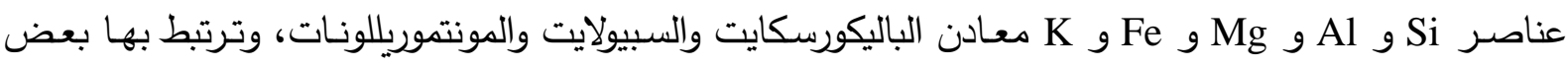
العناصر بصيغة الاحلال مثل Ti و Ga وبعض Cr و Vi او بصيغة الامتزاز مثل Zn و Cu و Ni و و Co

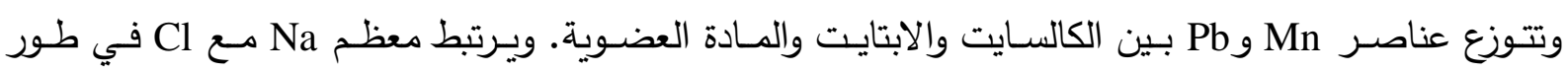
الهالايت.

يحل Sr في الفرانكولايت في الموقع Ca (I) ولا يعتقد انه يشغل الموقع Ca (II) لعدم ملائمة العدد التناسقي لهذا الموقع لتقبل Sr مr يعكس محتوى الفرانكولايت من Sr تأثير المياه البينية في رواسب قاع المحيط في المناطق العميقة (التي حصل لها اغتناء بـ Sr نتيحة تحلل قشور وأصداف الكائنات البحرية) في المراحل الأولية لتكوين الفرانكولايت.

يعتقد ان Y يشغل الموقع Ca (I) أكثر من الموقع Ca (II) في بلورة الفرانكولايت، ولذلك يعكس مرحلة تكوين الفرانكولايت من المياه البينية في رواسب القاع في المناطق العميقة. كما يمكن ان يكون بطور Xenotime, YPO4 تعكس علاقة Zr مع Zr إلى وجود طور فوسفاتي يغلف حبيبات الزركون، التي تعكس أيضا بيئة الجرف

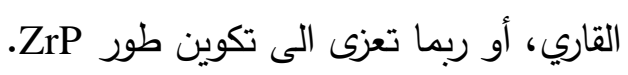
إن أكثر تركيز لا Uكون في الفرانكولايت، إذ يحل محل Ca في كلا الموقعين خلال مراحل تكوين

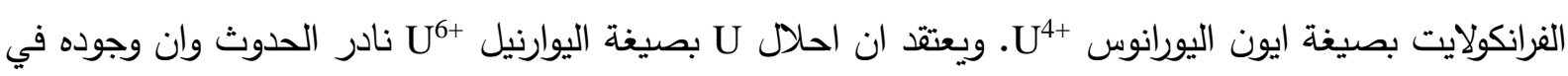
مواقع Ca هي بسبب النشاط الاشعاعي لليورانوس في هذه المواقع، أو يمتز على السطح الداخلي للقناة البلورية. فضلا عن وجوده في مجموعة معادن الكارنوتايت مثل اوتونايت وتيويامونايت وميتاتيويامونايت، وهي أطوار ثانوية تتكون نتيجة تجوية المعادن الفوسفاتية المحتوية على U. ويوجد U أيضا في نماذج الاسنان والعظام، 
بسبب قدرتها على التقاط U من المياه، وتثبيته بشكل ممتز على سطح المعدن الفوسفاتي. كما يحل محل Ca في معدن الكالسايت.

عادة ما يوجد الكروميوم والفناديوم في المعادن الطينية، وممكن ان يحل كل منهما بصيغة محل ${ }^{2} \mathrm{PO}_{4}$ المعادن الطينية المصاحبة للفرانكولايت.

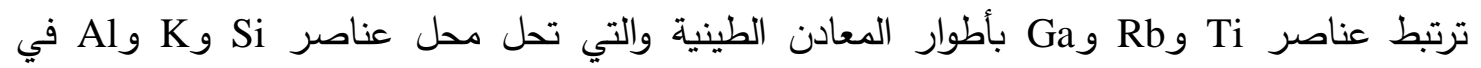
التركيب البلوري للمعدن الطيني. ومن الممكن ان توجد أيضا بشكل ممتز على أسطح المعادن الطينية. ولذلك تعكس نسب هذه العناصر مقدار التجهيز بالمواد الفتاتية في بيئة الجرف القاري. بعض العناصر الأثرية مثل Mn ممكن ان تتوزع بين أطوار الفرانكولايت والكالسايت حيث يحل محل

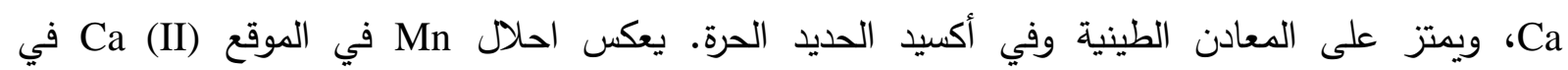
الفرانكولايت تأثير العمليات التحويرية ومقدار التجهيز بالمواد الفتاتية.

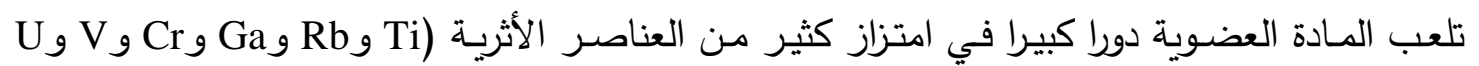

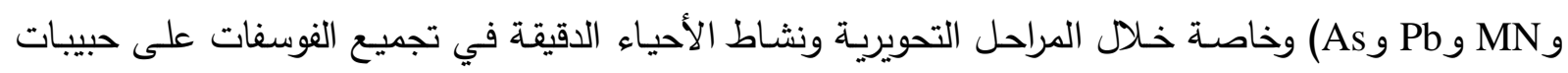
الفرانكولايت اثناء مرحلة النمو المتزايد للحبيبات الفوسفاتية.

\section{المصـادر العربية}

أبـا حسـين، اسـماء علـي عبـد الكرحمن، 1987. دراسـة جيوكيميائيـة وبتروغرافيـة ومعدنيـة لوحـدات الباليوسين الفوسفاتية في منطقة الكعرة - عكاشات. أطروحة دكتوراه غير منشورة، كلية العلوم، جامعة بغداد، 277 صفحة. محمد، ابراهيم قاسم، 1985. بتروغرافية وجيوكيميائية الصخور الفوسفاتية لعصر الكريتاسي الأعلى، الباليوسين

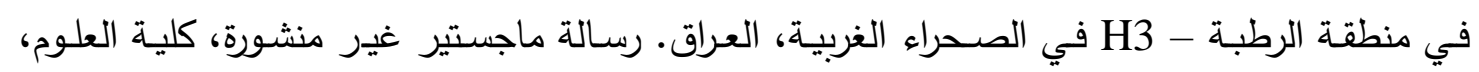
جامعة بغداد، 266 صفحة. اليوزبكي، قتيبة توفيق، 2004. الجوانب البتروغرافية والجيوكيميائية وتأثيرها على خطوط انتاج الأسمدة الوسفاتية ومطروحاتها، القائم - غربي العراق. أطروحة دكتوراه غير منشورة، كلية العلوم، جامعة الموصل، 278 ص. اليوزبكي، قتيبة توفيق والدباغ، سالم محمود، 2018. تقدير الصيغة الكيميائية لمعدن الفرانكولايت في فوسفورايت تكوين عكاشات من معطيات الأثعة السينية الحائدة، المجلة العراقية الوطنية لعلوم الأرض، المجلد 18،

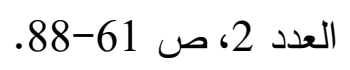

اليوزبكي، قتيبة توفيق والدباغ، سالم محمود، 2019. جيوكيميائية الفوسفورايت والصخور المصساحبة لها ضمن تكوين عكاشـات (الباليوسين الأوسط) في منجم عكاشـات، الصـحراء الغربيـة العراقيـة. الجزء الأول:

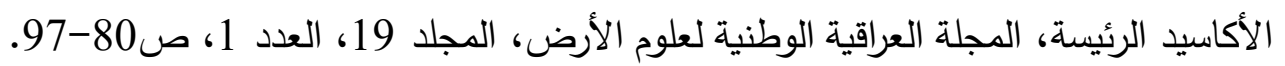




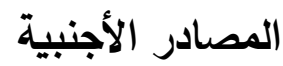

Al-Bassam, K. S., 1992. Gensis of the Late Cretaceous-Early Tertiary Phosphorites in Iraq. Iraqi Geological Jour., Vol. 25, No. 3, pp. 80-103.

Al-Bassam, K. S., Karim, S.A., Mahmoud, K. Yakta, S. A., Saeed, L. K. and Salman, M., 1990. Geological Survey of the Upper Cretaceous-Lower Tertiary Phosphorite-bearing Sequence, Western Desert, Iraq. Scale (1:25000). S.E. of Geological Survey and Mining. 208p.

Al-Dabbagh, S.M., 1989. Critical Review of the Geochemistry of Uranium Associated with Akashat Phosphorite (Paleocene) in the Western Desert, Iraq. Classified Report, INO. 19p.

Altschuler, Z.S., 1980. The Geochemistry of Trace Elements in Marine Phosphorite. Part I: Characteristic abundances and Enrichment. A Symposium of the $10^{\text {th }}$ Inter. Cong. on Sed. By Bentor, 1980 (Edi.) The Society of Economic Paleontologists and Mineralogists, 29, pp. 19-30.

Altschuler, Z.S., Berman, S. and Cuttitta, F., 1967. Rare Earth in PhosphoritesGeochemistry and Potential Recovery. U.S. Geol. Surv. Prof. Paper, 575-B, pp. 1-9.

Altschuler, Z.S., Clarke, R. S. and Young, E.J., 1958. Geochemistry of Uranium in Apatite and Phosphorite. Shorter Contributions to General Geology. Geological Surv. Prof. Paper 314-D, pp. 45-87.

Appanna, V.D. and Hamel, R.D., 1999. Metal Stress and Adatation in Pseudomonas Flourescens: New Prespectives. Recent Res. Devel. Microbiology, Vol. 3, pp. 615-663.

Barbarand, J., Carter, A., Wood, I. and Hurford, T., 2003. Compositional and Structural Control of Fission -track Annealing in Apatite. Chemical Geology, Vol. 198, No. (1-2), pp. 107-137.

Benmre, R. A., Coleman, M. L. and McArthur, J. M., 1983. Origin of Sedimentary Francolite from its Sulfur and Carbon Isotope Composition. Nature, No. 302, pp. 516-518.

Bremner, J.M., 1980. Concretionary Phosphorite from SW Africa. The Journal of the Geological Society, Vol. 137, Part VI, 773-785.

Calder, G.J. and Darwin, A., 1989. The Assessment and Use of Rock Phosphates as Fertiliser. Technote., Vol. 158, No. 9. (extend Abstract).

Dall Aglio, M., Gragnani, R. and Locardi, E., 1974. Geochemical Factors Controlling the Formation of the secondary Minerals of Uranium. Proceeding of the Symposium "Formation of the Uranium Ore Deposits "Inter. Atom. Ener. Agea. Vienna, pp.33-46. 
جيوكيميائية الفوسفورايت والصخور المصاحبة لها ضمن تكوين عكاشات (الباليوسين الأوسط)......

Dawson, J.B. and Hinton, R.W., 2003. Trace Element Content and Partitioning in Calcite, Dolomite and Aptite in Carbonatite, Phalaborwa, South Africa. Mineralogical Magazine, Vol. 67, No. 5, pp. 921-930.

Elbaz-Poulichet, F., Dupuy, C., Cruzado, A., Velasquez, Z., Achterberg, E.P. and Braungardt, C.B., 2000. Influence of Sorption Processes by Iron Oxides and Algae Fixation on Arsenic and Phosphate Cycle in an Acidic Estuary (Tinto River, Spain). Jour. Intern. Assoc. Water Quality, Vol. 34, No. 12, pp. 32223230 .

EPA, 1995. Technical Research Document, Extraction and Beneficiation of Ores and Minerals, Vol. 5 (Uranium). U.S. Environmental Protection Agency. 70p.

Fountain, K.B. and McClellan, G.H., 2000. Mineralogical and Geochemical Evidence for the Origin of Phosphorite Nodules on the Upper West Florida Slope. Marine Authigenesis: From Global to Microbial, SEPM. Special Publication No.66, Society of Sedimentary Geology No.66., pp. 201-220.

Gao, Y. and Mucci, A., 2003. Individual and Competitive Adsorption of Phosphate and Arsenate on Goethite in Artifical Seawater. Chemical Geology, Vol. 199, No. (1-2), pp. 91-109.

Harlov, D.E., Forster, H.J. and Schmidt, C., 2003. High P-T Experimental Metasomatism of a Fluorapatite with Significant Britholite and Fluorellestadite Components: Implication for LREE Mobility during Granulite-facies metamorphism. Mineralogical Magazine, Vol. 67, No. 1, pp. 61-72.

Hurlbut, C.S. and Klein, C., 1977. Manual of Mineralogy (after Dana, J.D.) 19 Edition. Tr. by Cornelius, et al., John Wiley \& Sons INC. New York. 532p.

Jarvis, I., 1980. Geochemistry of Phosphatic Chalks and Hardgrounds from the Santonian to Early Campanian (Cretaceous) of Northern France. The Journal of the Geological Society, Vol. 137, Part VI, pp. 705-721.

Jerden, J.L., Sinha, A.K. and Zelazny, L., 2003. Natural Immobilization of Uranium by Phosphate Mineralization in an Oxidizing Saprolite-soil Profile: Chemical Weathering of the Coles Hill Uranium Deposite, Virginia. Chemical Geology, Vol. 199 (1-2), pp.129-157.

Kostov, I., 1968. Mineralogy. Trans. by Oliver \& Boyd LTD. Printed by Robert \& Sons LTD. London, 587p.

Krauskopf, K.B., 1985. Introduction to Geochemistry. 2nd Edition, McGraw-Hill Book Company, New York, 617p.

Lanfranco, A.M., Schofeild, P.F., Murphy, P.J., Modson, M.E., Mosselmans, J.E. and Valsami-Jones, E., 2004. Characterization and Identification of Mixed-metal Phosphates in Soils: The Application of Raman Spectroscopy. Mineralogical Magazine, Vol. 67, No. 6, pp. 1299-1319. (Ext. Abstract). 
LeGeros, R.Z., 1999. Calcium Phosphate in Demineralizition/Remineralization Processes. Jour. Clin. Dent., Vol.10, pp.65-73.

McArthur, J.M., 1985. Francolite Geochemistry-compositional Controls during Formation, Diagenesis, Metamorphism and Weathering. Geochimica et Cosmochimica Acta, No. 49, pp. 23-35.

McClellan, G.H., 1980. Mineralogy of Carbonate-fluorapatite. Jour. Geol. Soc., Vol.137, Part VI, pp.675-681.

Milliman, J.D., 1974. Marine Carbonates. Recent sedimentary carbonates, Part I, Springer-Verlag, Berlin. 375P.

Millot, G., 1970. Geology of Clays. Springer-Verlag, New York, 429p.

Murray, H., 2002. Industrial Clays Case Study. Mining Minerals and Sustainable Development. Report No. 64, International Institute for Environment Development. IIED \& WBCSD.

Nath, B.N., Rao, B.R., Rao, K.M. and Rao, C.M., 2000. Rare-earth Elements and Uranium in Phosphatic Nodules from the Continental Margins of India. Marine Authigenesis: From Global to Microbial, SEPM. Special Publication No.66, Society of Sedimentary Geology No.66., pp.221-232.

Nathan, Y., 1984. The Mineralogy and Geochemistry of Phosphorites. Phosphate Minerals, Springer Verlag, New York, pp.275-291.

Navas, A. S. and Al-Garra, A. M., 2001. Genesis of Apatite in Phosphate Stromatolites. European Journal of Mineralogy, Vol. 13 (2).

Prevot, L. and Lucas, J., 1980. Behavior of some Trace Elements in Phosphatic Sedimentary Formations. A Symposium of the $10^{\text {th }}$ Inter. Cong. On Sed. By Bentor, 1980 (Edi.). The Society of Economic Paleontologists and Mineralogists, Vol. 29, pp.31-40.

Rakovan, J., Reeder, R. J., Elzinga, E., Cherniak, D. J., Tait, C. D. and Morris, D. E., 2002. Crystal Chemistry of U (VI) in Apatite Determined by X-ray Absorption Spectroscopy. Denever Annual Meeting (October 27-30, 2002). The Geological Society of America Publishing, Paper No. 138-4.

Rose, A.W., Haekes, H.E. and Webb, J.S., 1981. Geochemistry in Mineral Exploration. 2 ${ }^{\text {nd }}$ Edit. Academic Press, London. 657p.

Sen Gupta, J. G., 1977. Determination of Traces of Rare - Earth Element, Yttrium, and Thorium in Several International Geological Reference Samples and Comparison of Data with Other Published Values. Geostandards Newsletter, Vol. 1 (3), pp.149-155. 
Slansky, M., 1986. Geology of Sedimentary Phosphates. (Tr.) by Cooper, P. and Notholt, A., North Oxford Academic Publishers Ltd., 210p.

Stephan, A. and Richter, D.K., 2000 Preservation and Chemical Alteration of Biogenic Francolite and Calcite from Marine Organism. Journal of Conference Abnstracts (Cambridge Publications), Vol. 5 (2), pp. 466.

Tribble, J.S., Arvidson, R.S., Michael Lane III, M. L. and Mackenzie, F.T., 1995. Crystal Chemistry, and Thermodynamic and Kinetic Properties of Calcite, Dolomite, Apatite and Biogenic Silica: Applications to Petrologic Problems. Sedimentary Geology, Vol. 95, pp.11-37.

Van Olphen, H. and Veniale, F. (1981) Development in Sedimentology. International Clay Conf. Elsevier, Oxford, 827P.

Yamanaka, S. and Kaizumi, M., 1975. Structural Consideration of Zirconium Phosphate and its Organic Complexes. Clays and Clay Minerals, Vol. 23 (6), pp.477-478. 